\title{
Effect of Amine Nature on Rates and Mechanism: Pyridinolyses of 4-Nitrophenyl Benzoate
}

\author{
Ik-Hwan Um, ${ }^{*}$ Mi-Hwa Back, and Hyun-Joo Han \\ Deparmen of Chemistry, Ewha Womans University, Seoul 120-750. Korea \\ Received Aprl 21, 2003
}

\begin{abstract}
Pseudo-first-order rate constants $\left(k_{\text {chs }}\right)$ have been measured spectrophotometrically for the reactions of 4nitrophenyl benzoate with a series of pyridines in $\mathrm{H}_{2} \mathrm{O}$ containing $20 \mathrm{~mol} \%$ DMSO. The plots of $k_{\text {chls }} v s$ pyridine concentration are linear up to ca. $0.1 \mathrm{M}$ pyridines, indicaling that the effect of self-association of pyridines with their conjugate acids are insignificant in this concentration range. The Bronsted-1ype plot has been obtained to be linear with a $\beta_{\text {tute }}$ value 1.11 , suggesting that the pyridinolyses proceed through a ratedetermining breakdown of the zwiterionic addition intermediate. The pyridines studied have shown higher reactivity than isobasic primary and sccondary amines toward the substrate. 1-Benzoyl-4-dimethylaminopyridinium ion, a possible intermediate. has not been detected since the rate of its hydrolysis in the reaction condition is comparable with or even faster than its formation.
\end{abstract}

Key Words : Pyridinolysis, Bronsted-type plot, Rate-determining step

\section{Introduction}

Aminolyses of esters have widely been investigated due to the interest in biological processes as well as in synthetic applications. $^{1-5}$ The reactions have been understood to proceed through an addition intermediate, $T$ : in which the rate-determining step is dependent on the basicity of the leaving group and the attacking amine, i.e., the ratedetermining step changes from the breakdown of $\mathrm{T}^{\prime}$ to the products to the formation of $\mathrm{T}^{\prime}$ as the attacking amine becomes more basic than the leaving group by 4-5 $\mathrm{p} K_{\mathrm{a}}$ units. $^{1-5}$

Aminolyses of esters with a poor leaving group or those with a $\mathrm{C}^{-} \mathrm{S}$ bond (e.g.. a thiono ester in Scheme 1) have often been reported to proceed through a rate-determining deprotonation step ( $c .3$. the $k_{3}$ step) ${ }^{1-5}$ Lee et al. have suggested that the $k_{3}$ process observed in aminolyses of thiono esters performed in aqueous medium is due to the anomalously fast rate of proton transfer in water. ${ }^{\text {ta }}$ We have recently performed aminolyses of $O$-4-nitrophenyl thiono- benzoate, and found that the reactions with various secondary amines (either cyclic or acyclic) proceed through the $k_{3}$ path. ${ }^{\varsigma}$ However, the corresponding reactions with primary amines proceeded without the $k_{3}$ step. ${ }^{\text {sandicating }}$ that the amine nature influences the reaction mechanism.

We have been investigating the effect of the amine nature on rates and mechanisms. Pyridinolyses of esters have been suggested to be simple with no complications arising from the $k$; process. ${ }^{6-8}$ However, pyridines are known to exhibit unusual behavior in aminolyses of esters compared with primary and secondary amines. ${ }^{6-8}$ The aim of this work is to investigate the effect of the amine nature on rates and mechanisms, and to shed more light on the unusual behavior shown by pyridines in pyridinolyses.

\section{Experimental Section}

Materials. 4-Nitrophenyl benzoate (PNPB) was prepared easily form the reaction of benzoyl chloride and 4-nitrophenol in anhydrous ether in the presence of triethylamine.

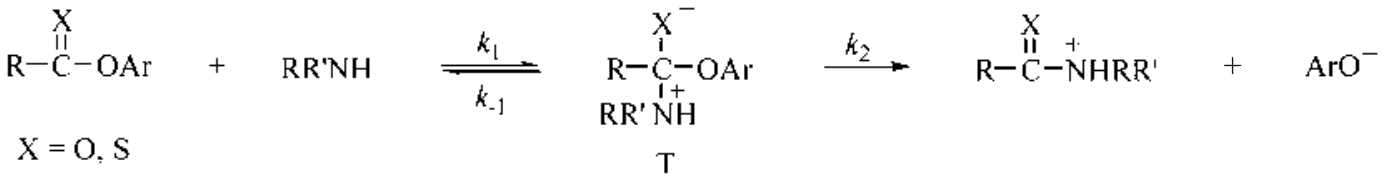

$$
\begin{aligned}
& -H^{+} \mid k_{3}\left[R^{\prime} N H\right]
\end{aligned}
$$

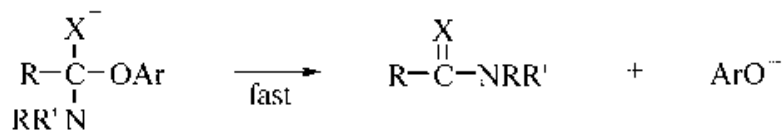


The purity of PNPB was checked by means of melting point and spectral data such as IR and 'H NMR characteristics. Pyridines were of the highest quality available. Doubly glass distilled $\mathrm{H}_{2} \mathrm{O}$ was further boiled and cooled under nitrogen just before use. The reaction medium was $\mathrm{H}_{2} \mathrm{O}$ containing 20 mol \% DMSO due to low solubility of $\mathrm{P}^{\mathrm{N} P B}$ in $\mathrm{H}_{2} \mathrm{O}$.

Kinetics. The kinetic study was performed with a Scinco S-2100 PDA UV-vis spectrophotometer equipped with a Neslab RTE-I 10 constant temperature circulating bath to keep the temperature in the reaction cell at $25.0+0.1{ }^{\circ} \mathrm{C}$. The reaction was followed by monitoring the appearance of the leaving 4-nitrophenoxide (or 4-nitrophenol for the reactions with low basic pyridines). All the reactions were carried out under pseudo-first-order conditions in which the pyridine concentrations were much greater than the substrate concentration. The pyridine stock solution of $c a .0 .2 \mathrm{M}$ was prepared by dissolving 2 equiv of pyridine and 1 equiv of standardized $\mathrm{HCl}$ solution to keep the $\mathrm{pH}$ constant by making a self-buffered solution. All the solutions were prepared freshly just before use and transferred by Hamilton gas-tight syringes.

Determination of $\mathrm{p} K_{\mathrm{a}}$. The $\mathrm{p} K_{\mathrm{it}}$ values of conjugate acids of pyridines were determined by measuring the $\mathrm{pH}$ of the solution containing equal amounts of pyridine and pyridine hydrochloride with a glass electrode. The $\mathrm{pH}$ measurements were performed in a pyridine concentration range (10-100) $\times 10^{-3} \mathrm{M}$, in which most of the rate constants were measured.

Product Analysis. 4-Nitrophenoxide (and/or 4-nitrophenol) and benzoate were identified as the products of the pyridinolyses of PNPB by comparison of the UV-vis spectrum at the end of reactions with the authentic sample under the kinetic experimental conditions.

\section{Results and Discussion}

Reactions of 4-nitrophenyl benzoate with pyridines proceeded with quantitative liberation of 4-nitrophenoxide and or its conjugate acid. All the reactions obeyed first-order kinetics over $90 \%$ of the reaction. Pseudo-first-order rate constants $\left(k_{\omega b s}\right)$ were determined from the equation $\ln \left(A_{00}-\right.$ $\left.A_{1}\right)^{-}-k_{\mathrm{obs}} \mathrm{t}+\mathrm{c}$. The kinetic results obeyed the simple kinetic law given by eqs. (1) and (2). The second-order rate constants $\left(k_{\mathrm{N}}\right)$ were determined from the linear plots of $k_{0}$ os $v$ pyridines concentration. The kinetic results are summarized in Table 1 and demonstrated graphically in Figures $I$ and 2.

$$
\begin{gathered}
\mathrm{d}[\mathrm{P}] / \mathrm{dt}=k_{\mathrm{ols}}[\mathrm{PNPB}] \\
k_{\mathrm{obs}}-k k_{2}[\text { pyridine }] . \\
\text { where } k_{\mathrm{N}}-k_{1} k_{2}\left(k_{1}+k_{2}\right)
\end{gathered}
$$

Effect of Self-Association of Pyridines on Rates. As shown in Figure I, the plots of $k_{0 b s} w$ the concentration of pyridines are linear up to ca. $0.1 \mathrm{M}$ pyridines. Such linear plots are contrasting with the downward curvatures observed in the corresponding plots for pyridinolyses of various esters. Castro et al. have observed a downward curvature in the plot of $k_{01 \%}$ against the pyridine concentration for the reactions of 2.4-dinitrophenyl benzoate with a series of substituted pyridines in aqueous ethanol. ${ }^{0}$ A similar result has been reported for the reactions of 4-nitrophenyl phosphate dianion with various substituted pyridines in aqueous solutions. ${ }^{3}$

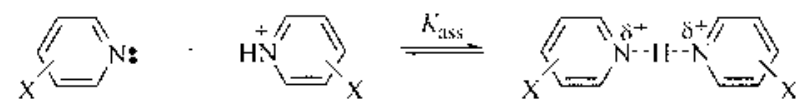

\begin{tabular}{|c|c|c|c|c|}
\hline Amine & $\mathrm{p} K_{a}^{\prime \prime}$ & [amine] $\mathrm{mM}$ & $10^{3} k_{0} b / s^{-1}$ & $10^{3} k_{N} \mathrm{M}^{-1} \mathrm{~s}^{-1}$ \\
\hline I. 3-methy]pyridine & 5.09 & $20.1-98.5$ & $0.00761-0.0133$ & 0.00898 \\
\hline 2. 4-methylpyridine & 5.53 & $19.3-101$ & $0.0123-0.0481$ & 0.0419 \\
\hline 3. 3.4-dimethylpyridine & 5.78 & $18.7-131$ & $0.0280-0.108$ & 0.0836 \\
\hline 4. 4-aminopyridine & 8.93 & $19.2-141$ & $2.55-19.1$ & 193 \\
\hline 5. 4-dimethylaminopy ridine & 9.12 & $19.3-142$ & $5.26-35.3$ & 347 \\
\hline 6. urilluoroethylamine" & 5.70 & - & - & 0.0667 \\
\hline 7. glycine ethyl ester & 7.68 & - & - & 10.6 \\
\hline 8. glycylglycine & 8.31 & - & - & 250 \\
\hline 9. benzylamines" & 9.46 & - & - & 242 \\
\hline 10. ethanolamine & 9.67 & - & - & 340 \\
\hline II. glycine & 10.06 & - & - & 604 \\
\hline 12. ethylamine" & 10.67 & - & - & 1970 \\
\hline 13. piperdyinium iom ${ }^{\circ}$ & 5.95 & - & - & 0.460 \\
\hline 14. morpholine & 8.65 & - & - & 84.1 \\
\hline 15. piperdine & 9.85 & - & - & 841 \\
\hline 16. 3-mfethyl piperidine & 10.80 & - & - & 3550 \\
\hline 17. piperidine" & 11.02 & - & - & 5290 \\
\hline
\end{tabular}

Table 1. Summary of the kinetic results for aninolyses of PNPI3 with pyridines. primary and alicyclic secondary amines in 20 inol \% $\mathrm{DMSO}$ at $25.0+0.1^{\circ} \mathrm{C}$ '

"pKa values determined in $20 \mathrm{~mol} \% \mathrm{DMSO}$ at $25.0-0.1{ }^{\circ} \mathrm{C}$. " lhe data for primary amines were taken lrom rel 5 (b). "The data for secondary amines were takin from ref $5(\mathrm{c})$. 


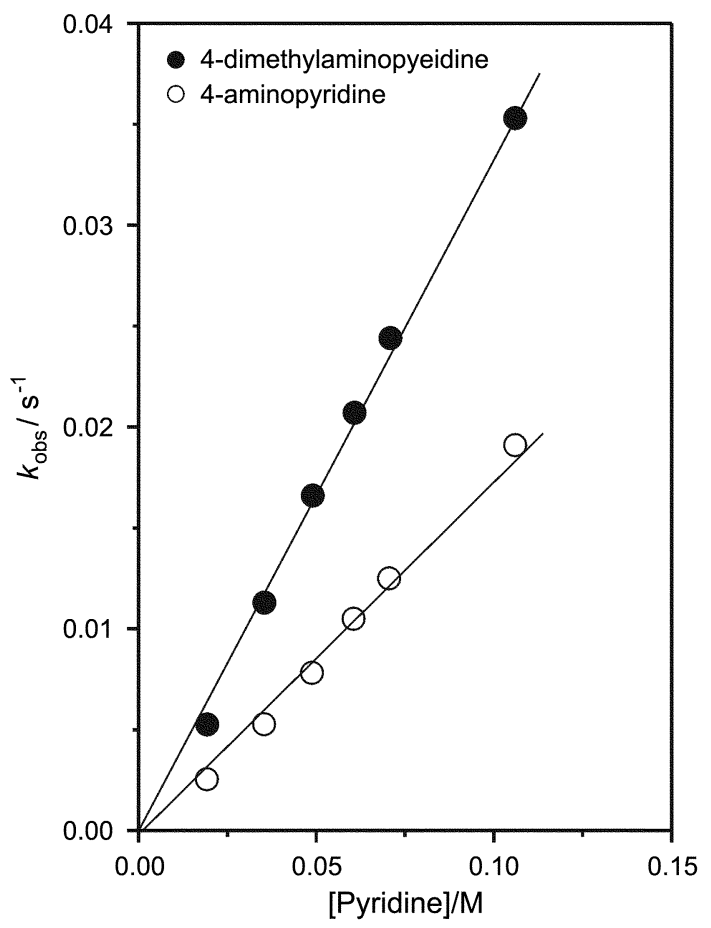

Figure 1. Plots of $k_{\text {uls }} w s$ pridine concentration for the reaction of PᄉPB with 4-dimethylaminopyridine (๑) and 4-aminopyridine (i) in $20 \mathrm{~mol} \%$ DMSO at $250 \pm 0.1$ 'C.

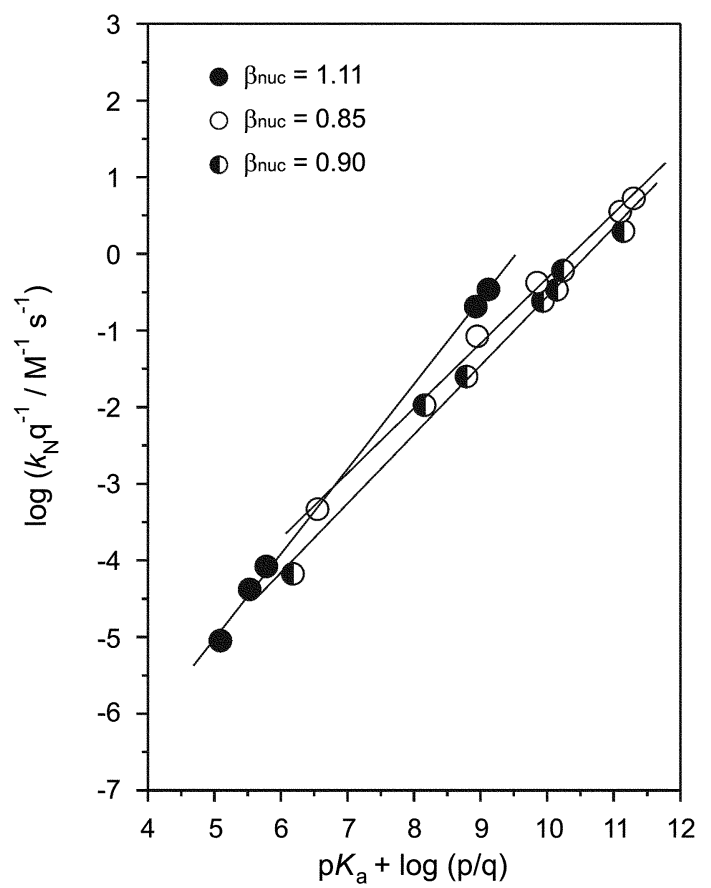

Figure 2. Bronsted-type plots for reactions of PNPI3 with substituted pyridines $(\bullet)$ and alicyelic secondary $(\cdots)$ and primary ( 1 ) amines in $20 \mathrm{~mol} \%$ DMSO at $25.0+0.1^{\circ} \mathrm{C}$.

The downward curvature has been attributed to a selfassociation effect of pyridines, i.e., pyridines undergo selfassociation with their conjugate acids with an association constant $K_{\text {ats. }}^{\text {as }}$ as shown in eq. (3). ${ }^{6-8}$ The degree of such selfassociation would increase with increasing the concentration of pyridines, and the associated species would be unreactive. This argument is consistent with the fact that downward curvatures have generally been found to be more significant in a higher pyridine concentration region. However, if the association of pyridines with their conjugate acids were solely responsible for the decreased reactivity with increasing pyridine concentration, a downward curvature should have been obtained in the plot of $k_{0 b s} v s$ pyridine concentration for the present pyridinolyses. As shown in Figure 1, the plots of $k_{0}$ is $w$ pyridine concentration are clearly linear up to $c a .0 .1 \mathrm{M}$ pyridine. Therefore, the present result suggests that the downward curvature observed previously ${ }^{60.8}$ is not necessarily due to the self-association effect of pyridines. This argument can be further supported from the fact that a marked leveling off of the rate with increasing the concentration of pyridines has been reported for the pyridinolyses of acetic anhydride in a pyridine concentration below $0.08 \mathrm{M}^{8}{ }^{8}$ Furthermore, the plots of $k_{\text {obs }} w$ pyridine concentration have been obtained to be linear for the pyridinolyses of various esters (e.g., 2.4-dinitrophenyl 4chlorobenzoate." 4-nitrophenyl 4-methylphenyl thionocarbonate, ${ }^{10}$ bis(4-nitrophenyl) thionocarbonate. ${ }^{11}$ aryl furan-2carbodithioate, ${ }^{12}$ aryl dithioacetates, ${ }^{1.3}$ thiophenyl 4-nitrobenzoate ${ }^{14}$ and aryl phenyl chlorophosphate ${ }^{15}$ ) performed in aqueous medium ${ }^{9 / 11}$ as well as in a dipolar aprotic solvent such as $\mathrm{MeCN} \cdot{ }^{12-15}$ Accordingly, one can suggest that the nature of the substrate also influences the downward curvature in the plot of $k_{\text {cols }}$ ws pyridine concentration.

Effect of Amine Nature on Mechanism. The $\mathrm{p} K_{\mathrm{a}}$ values of the conjugate acids of pyridines have been determined in $\mathrm{H}_{2} \mathrm{O}$ containing $20 \mathrm{~mol} \%$ DMSO, in which the kinetic studies were performed. It has been reported that oxygen acids such as phenols and carboxylic acids become weaker acids in aprotic solvents such as DMSO and MeCN due to the repulsion between the negatively charged oxyanion and the negative dipole end of these solvents, i.e. the $\mathrm{p} K_{\mathrm{a}}$ of benzoic acid and phenols increases by 6.9 and $10.0 \mathrm{p} K_{\mathrm{il}}$ units as the medium changes from $\mathrm{H}_{2} \mathrm{O}$ to DMSO.${ }^{16}$ However, the effect of medium on the basicity of nitrogen acids (eg., amines) has been reported to be much less significant than that of oxygen acids. ${ }^{17}$ Furthermore, some amines have been found to be even weaker bases in DMSO than in $\mathrm{H}_{2} \mathrm{O}$, i.e., the $\mathrm{p} K_{\mathrm{i}}$ values of aniline and piperidine have been reported to be 4.58 and 11.22 in $\mathrm{H}_{2} \mathrm{O}$ and 3.6 and 10.8 in DMSO, respectively. ${ }^{18}$ The pyridines used in the present study have been determined to be ca. 0.4-0.9 $\mathrm{pK}_{\text {at }}$ units less basic in 20 mol \% DMSO than in $\mathrm{H}_{2} \mathrm{O}$. This result appears to be consistent with the generally reported $\mathrm{p} K_{\mathrm{a}}$ values of nitrogen acids upon changing the medium from $\mathrm{H}_{2} \mathrm{O}$ to aqueous DMSO.

Table I shows that the second-order rate constant $\left(k_{N}\right)$ increases as the basicity of pyridines increases, i.e.., the $k \mathrm{v}$ value increases from $8.98 \times 10^{-6} \mathrm{M}^{-1} \mathrm{~s}^{-1}$ to $4.19 \times 10^{-5} .8 .36$ $\times 10^{-5}, 0.205$ and $0.343 \mathrm{M}^{-1} \mathrm{~s}^{-1}$ as the $\mathrm{p} K_{\mathrm{a}}$ of pyridines increases from 5.09 to $5.53,5.78,8.93$ and 9.12 , respectively. The effect of the basicity on the reactivity of pyridines is demonstrated in Figure 2. One can see a linear Bronsted- 


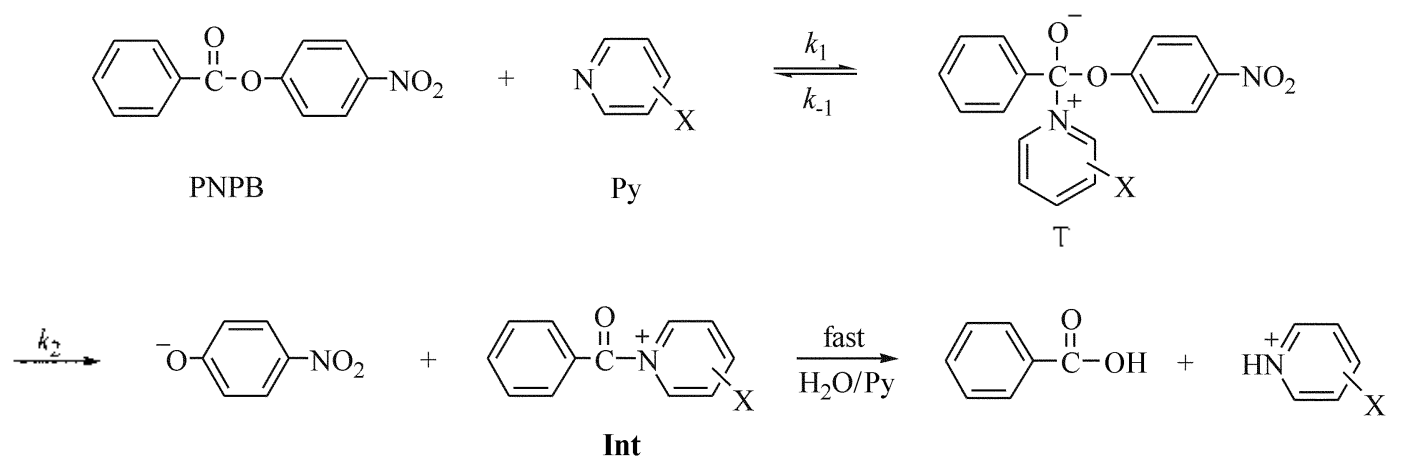

Scheme 2

type plot with a $\beta_{\text {nuc }}$ value I.1I for the pyridinolysis of PNPB. The corresponding plots for the reactions with the primary and secondary amines are also linear with $\beta_{\text {nuc }}$ values of 0.90 and 0.85 , respectively. The magnitude of the $\beta_{\text {nuc }}$ value is much larger for the reactions with the pyridines than for those with the primary and secondary amines. However, this is not so surprising since such a large $\beta_{\text {nuc }}$ value for the reactions with pyridines has often been observed for pyridinolyses of various esters, e.g. 3-nitrophenyl 4methyl thionocarbonate $\left(\beta_{\text {nu: }}-1.2\right){ }^{10}$ bis(4-nitrophenyl) thionocarbonate $\left(\beta_{\text {muc }}-1.0\right)$." alkyl aryl thionocarbonate $\left(\beta_{\text {uuc }}-1.0\right) .^{19}$ Therefore, it appears to be common that the positive charge developed at the nitrogen atom of the transition-state would be more significant for the reactions with the pyridines than for those with the primary and secondary amines.

The fact that there is no curvature in the Bronsted-type plot with a $\beta_{\text {uc }}$ value 1.11 suggests that the present pyridinolyses proceed through an addition intermediate $\mathrm{T}^{+}$in which the breakdown of $\mathrm{T}^{-}$to the products is the ratedetermining step. The linear Bronsted-type plots with large $\beta_{\text {nuc }}$ values shown in Figure 2 clearly indicate that the effect of the amine nature on the reaction mechanism is insignificant for the reactions of PNPB with pyridines, primary and secondary amines. This is quite contrasting with the results obtained from the previous studies. Castro $t$ al. have found that the Bronsted-type plot for the reactions of 0 -ethyl $S$-4nitrophenyl carbonate with secondary amines is nonlinear,

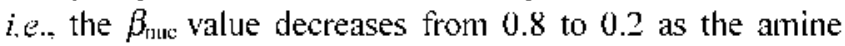
becomes highly basic. ${ }^{20}$ However, the Brønsted-type plot for the corresponding reactions with pyridines has been obtained to be linear with a $\beta_{\text {uuc }}$ value $0.8^{20}$ Similarly, the Bronsted-type plot for the reactions of bis(4-nirtrophenyl) thionocarbonate with pyridines has been reported to be linear with $\beta_{\text {uxc }}-1.0$, while the one with secondary amines exhibits a nonlinear Bronsted-type plot with changing the $\beta_{\text {uluc }}$ value from 0.45 to $0 . \mathrm{I}$ as the secondary amines becomes highly basic."

The nature of amines has also been suggested to influence the position of $p K_{a}^{\circ}$, the center of the curvature in a Bronsted-type plot. Castro et al. have found that the Bronsted-type plots are nonlinear for the reactions of 2,4dinitrophenyl acetate with secondary amines as well as for those with pyridines. ${ }^{2]}$ However, the $p K_{a}{ }^{0}$ has been determined to be 7.3 and 9.1 for the reactions with pyridines and secondary amines, respectively, ie, a decrease in the $\mathrm{p} K_{\mathrm{a}}{ }^{\circ}$ value of $1.8 \mathrm{p} K_{a}^{\circ}$ units upon changing the amine nature from pyridines to secondary amines. ${ }^{21}$ A remarkably decreased $\mathrm{p} K_{\mathrm{i}}{ }^{\circ}$ value has also been reported for pyridinolyses of various thio and dithio esters. Lee $e t a l$. have reported the $\mathrm{p} K_{\mathrm{it}}{ }^{\circ}$ value is 5.2 for the pyridinolyses of aryl furan 2carbodithioates $^{12}$ and aryl dithioacetates, ${ }^{13}$ and 4.2 for the pyridinolyses of thiophenyl 4-nitrobenzoates in $\mathrm{MeCN} .^{1+}$ Therefore, the effect of the amine nature on the $p K_{i 1}^{\circ}$ value appears to be also dependent on the nature of the substrates.

Effect of Amine Nature on Rates. As shown in Figure 2, pyridines are more reactive than isobasic primary and secondary amines. The reactivity order observed in this study is consistent with the generally reported reactivity order. $^{10.11 .22}$ Tertiary amines have been reported to be more reactive than isobasic primary and secondary amines, just as in the present study, for deprotonation of various $\mathrm{C}-\mathrm{H}$ acids (e.g.. phenylnitromethane. ${ }^{2.3} 4$-nitrophenylacetonitritrile. ${ }^{2+}$ 9carbomethoxyfluorene, ${ }^{25}$ 9-fluorenylmethyl chloride ${ }^{26}$ ), and for additions to activated ethylenes ( $e . g .$, benzylidene Meldrum's acid $^{27}$ and $\beta$-methoxy- $\alpha$-nitrostylbene ${ }^{28}$ ). The reactivity trend was attributed to decreasing solvation in the order $\mathrm{RNH}_{3}^{+}>$ $\mathrm{R}_{2} \mathrm{NH}_{2}{ }^{+}>\mathrm{R}_{3} \mathrm{NH}^{+}$, i.e. primary amines, whose ammonium ions are relatively highly solvated, are less effective kinetically than would be predicted on the basis of their $p K_{\mathrm{i} 1} \mathrm{~s}^{22-28}$

One can analyze the reactivity order in a quantitative way. As mentioned above, the present aminolyses of PNPB proceed through an addition intermediate and its breakdown is the rate-determining step. In this case, $k_{-1}>k_{2}$ and then eq. (2) becomes eq. (4). Since the $k_{z}$ value has been suggested to be insensitive to the basicity and nature of amines, the magnitude of the $k_{\wedge}$ value is dependent on the $k_{1} / k_{-1}$ ratio. Therefore, one can expect the $k_{1} / k_{-1}$ ratio for pyridines should be larger than that for secondary and primary amines either by increasing the $k_{1}$ value or by decreasing the $k_{-1}$ value. In fact, Castro ${ }^{|0,1|}$ and Lee et $a l^{12}$ have reported that the $k_{-1}$ value is smaller for the reactions with pyridines than for those with secondary amines.

$$
k_{N}=k_{\mid} k_{2} / k_{-1}
$$

As mentioned in the experimental section, the final 
products were benzoate and 4-nitrophenoxide (and/or its conjugate acid) for the pyridinolyses of PNPB. The plausible products in the present pyridinolyses, I-benzoyl-substituted pyridinium ions (Int, in Scheme 2), have not been detected by the competitive UV scanning (320-480 nm). One can suggest two possible reasons for this result. The pyridines could have behaved as a general base catalyst as shown in eq. (5). but not as a nucleophile. In this case, 1-benzoyl substituted pyridinium jons can not be formed. However, the pyridinium ions could have been undetected due to their low stability in the reaction condition. The absence of an isosbestic point in the present reactions of pyridines with

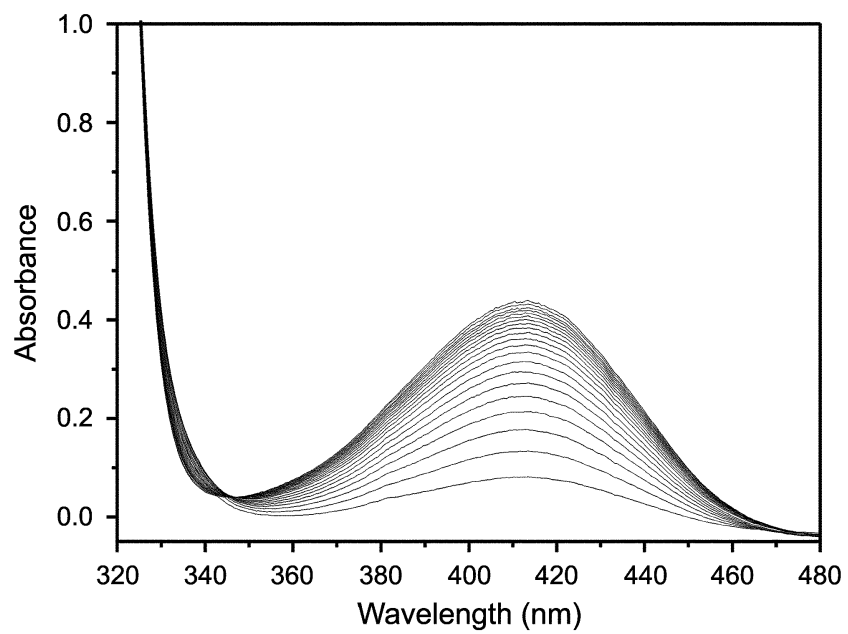

Figure 3. Repetitive LV-is spectra showing absence of an isosbestic point (ca. 340-350 rmm) for the reaction of DNPB with 4 dimethylaminopyridine in $20 \mathrm{~mol} \% \mathrm{I} \mathrm{MSO}$ at $25.0^{\circ} \mathrm{C}$. [INAPI3] $=$ $2.66 \times 10^{-5} \mathrm{M}$. Ipyridine $=0.0646 \mathrm{M}$. time intervals $=10$ seconds.

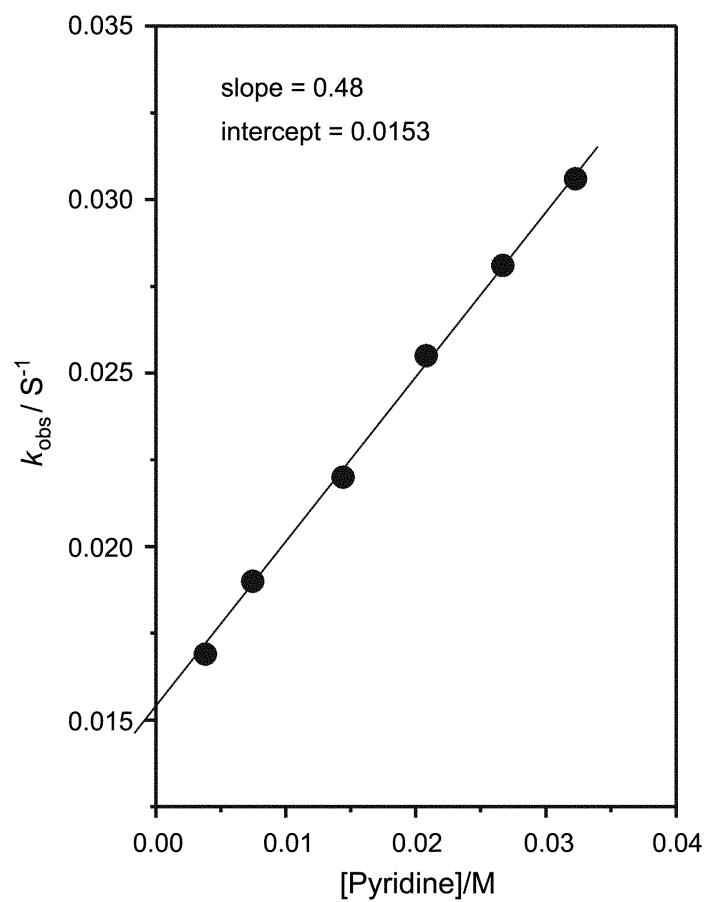

Figure 4. Plot of $k_{s, 3} v s$ py ridine concentration for the hydrolysis (decomposition) of 1-benroyl-4-dimethylaminopyridinium ion in $20 \mathrm{~mol} \% \mathrm{IMMSO}$ at $25.0-0.1^{\circ} \mathrm{C}$.
Table 2. Summary of the results for the hydrolysis (decomposition) of ]-ben\%yl-4-dimethylaminopyridinium ion in $20 \mathrm{~mol} \% \mathrm{JMSO}$ at $25.0-0.1$ " $\mathrm{C}$

\begin{tabular}{ccc}
\hline Pyridine $/ \mathrm{mM}$ & $10^{3} \mathrm{k}_{\mathrm{cll}} / \mathrm{s}^{-1}$ & $t_{12} / \mathrm{s}$ \\
\hline 32.3 & 30.6 & 22 \\
26.7 & 28.1 & 24 \\
20.8 & 25.5 & 27 \\
14.4 & 22.0 & 31 \\
7.45 & 19.0 & 36 \\
3.80 & 16.9 & 41 \\
\hline
\end{tabular}

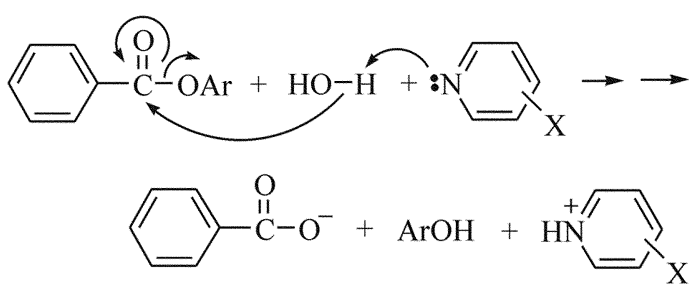

PNPB strongly supports the existence of pyridinium ions (See Figure 3).

In order to examine the stability of the pyridinium ions, we have produced I-benzoyl-4-dimethylaminopyridine ion by mixing the solutions of 2,4-dinitrophenyl benzoate and 4dimethylaminopyridine, and determined its hydrolysis rate in sith, eq. (6). The results are summarized in Table 2 and demonstrated graphically in Figure 4. One can see that the rate of decomposition increases with increasing the pyridine concentration. The half-life $\left(t_{1: 2}\right)$ is $c a .22-4 I$ seconds in a pyridine concentration range $3.80-32.3 \mathrm{mM}$. As shown in Figure 4 , the plot of the $k_{01} w$ w pyridine concentration is linear with a positive intercept, which represents the rate of hydrolysis of the pyridinium ion in the absence of 4 dimethylaminopyridine. The intercept was determined to be $0.0153 \mathrm{~s}^{-1}$, and therefore the half-life of the hydrolysis of Ibenzoyl-4-dimethylaminopyridinum ion is $c a .45$ seconds in the absence of the general base, 4-dimethylaminopyridine. The rate of decomposition of this pyridinium ion, which is the most stable among the plausible pyridinium ions in this study, is comparable with (or even faster than) that of its formation. Therefore, these pyridinium ions could not be detected during the pyridinolyses of PNPB by competitive UV-scanning due to their low stability in the reaction condition.

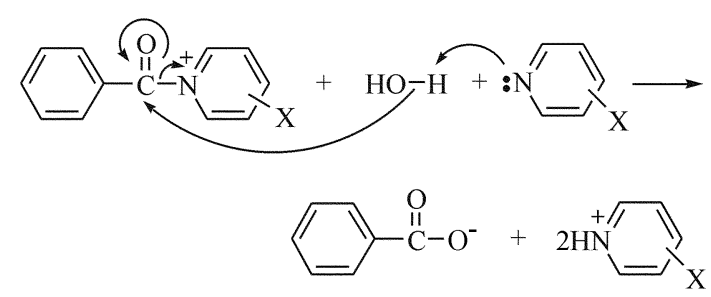

\section{Conclusions}

The present study has allowed us to conclude the following. (1) The effect of self-association of pyridines with 
their conjugate acids is not solely responsible for the downward curvatures which have often been observed in pyridinolyses. (2) The reactions of PNPB with pyridines proceed through an addition intermediate. $\mathrm{T}^{ \pm}$in which its breakdown to the products is the rate-determining step. (3) The effect of the amine nature on the reaction mechanism appears to be insignificant in the aminoly'ses of PNPB below $0.1 \mathrm{M}$ pyridines. (4) Pyridines are more reactive than isobasic primary and secondary amines. (5) 1-benzoyl substituted pyridinium ions are not stable enough to be detected during the reaction of PNPB with pyridines by the competitive UV-scanning.

Acknowledgment. This work was supported by a Korea Research Foundation Grant (015-CP0223).

\section{References}

1. (a) Satterthwait. A. C.: Jencks. W. P. J. Am Chem. Soc. 1974. 96. 7018-7031. (b) Stefanidis. D.: Cho. S.: Dhe-Paganon. S.: Jencks. W. P. J. Am. Chem. Soc. 1993. 115. 1650-1656. (c) Jencks. W. P. Brant, S. R: Gandler. J. R: Fendrich, G.: Nakamura, C. J. Am. Chem. Soc. 1982. 104.7045.7051

2. (a) Menger. F. M; Sinith, I. H. J. Am. Chem. Soc, 1972, 94, 38243829. (b) Menger. F. M.: Eliseev. A. V.: Khaniin. N. A.: Sherrod. M. J. J. Org (Chem. 1995, 60.2870-2878. (c) Adalsteinsson. H.: Bruice. T. C. J. Am. Chent Soc. 1998. 120.3440-3447.

3. (a) Castro. E. A.: Galvez. A.: Leandro. L.: Santos. J. G. J. Org. Chem. 2002, 67, 4309-4315. (b) Castro. E. A.: Leandro. L: Quesieh, N.: Santos. J. G. J. Org. Chem. 2001, 66,6130-6135. (c) Castro, E. A.: Saavedra, C.: Santos, J. G.; Umana, M. I. J. Org. Chem. 1999, 64. 5401-5407. (d) Castro. E. A.: Cubillos. M: Santos. J. G. J. Org. Chem. 1996. 61.3501-3505. (e) Castro. E. A.: Ibanez. F.: Santos. J. G.: Ureta. C. J. Org. Chem. 1993. 58. 49084912.

4. (a) Oh, H. K.: Woo, S. Y: Shin. C. H.: Park, Y. S.: Lee. I. J. Org. Chem. 1997. 62. 5780-5784. (b) Koh, H. J. Han, K. L.: Lee, H. W. Lee. I. Bull. Korean Chem. Soc. 2002. 23. 715-720. (c) Oh. H. K.: Kim. S. K.: Lee. H. W.: Lee. I. J. Chem. Soc. Perkin Trans. ? 2001. 1753-1757. (d) Lee. I.: Lee. H. W.: Lee. B. C.: Choi. J. H. Bull. Korean Chem. Soc. 2002. 23, 201-204. (e) Song. H. B: Choi, M. H.: Koo, I. S.: Oh, H. K.: Lee. I. Bull Korean Chem. Soc. 2003. $24.91-94$
5. (a) Um, I. H.: Lee, S. E; Kwon. H. J. J. Org. Chem. $2002,67$. 8999-9005. (b) Um. I. H.: Chun1g. E. K.: Lee. S. M. Can. J. Chem. 1998. 76. 729-737. (c) Um. I. H.: Kwonl. H. I.: Kwonl. D. S.: Park. J. Y. J.Chent Res. (1) 1995. 1801-1817. (d) Um. I. H.: Lee. E. T.: Lee. J. P. Bull, Korean Chent Soc. 2002, 23,381-384

6. Castro. E. A.: Santander. C. L. J. Org. Chem. 1985. 50. 35953600 .

7. Kirby. A. J.: Tencks. W. P. J. Am Chem Soc. 1965. 87. 32093216 .

8. Fersht. A. R.: Jencks. W. P. J. Ant Chem. Soc, 1970. $92.5432-$ 5442 .

9. Castro. E. A.: Valdivia J. L. J. Org. Chen. 1986. 51, 1668-1672.

10. Castro. E. A.: Garcia. P.: Leandro. L.: Quesieh. N.: Rebolledo, A.: Santos. J. G. J. Org. Chem 2000. 65,9047-9053

11. Castro. E. A.: Santos. T. G.: Tellez. T.: Unnana. M. I. J. Org. Chem. 1997.62.6568-6574.

12. Oh. H. K.: Ku. M. H.: Lee. H. W.: Lee. I. J. Ong Chem. 2002.67. $8995-8998$

13. Oh. H. K: Ku. M. H. Lee. H. W. Lee. I. I. Ong Chem. 2002.67. 3874-3877.

14. Koh. H. T.: Han1. K. L.: Lee. I. J. Org Chem 1999. 64. 4783-4789.

15. Guha. A. K.: Lee. H. W. Lee. I. J. Ong Chent 2000. 65. 12-15.

16. Buncel. E.: Wilson. H. Adh: Phs Org Chem. 1977. 1t. 133-202.

17. Um. I. H; Lee, E. J.: Jeon. S. E. J. Phws. Org. Chem. 2002, 15. $561-565$.

18. Kolthoff, I. M: Chantooni. M. K: Bhowmilk, S. J. Am. Chem. Soc. 1968. 90.23-28.

19. Castro. E. A.: Cubillos. M.: Santos. T. G.: Tellez. I. J. Org Chen. 1997.62.2512-2517.

20. Castro. E. A.: Pizarro. M. I.: Santos. J. G. J. Org. Chem. 1996, 6I. 5982-5985.

21. Castro. E. A.: Ureta C. J. Org. Chem. 1990. 55. 1676-1679.

22. Jencks. W. P. Catalysis in Chemistry and Enzymology: MeGrawHill: New York. 1969: p 179

23. Bernasconi. C. F.: Kliner. D. A.: Mullin. A. S.: Ni. I. X. J. Ong Chent 1988, $53,3342-3351$.

24. Bernasconi, C. F.: Hibdon, S. A. I. Am. Chem Soc, 1983. 105. $4343-4348$

25. Bernasconi. C. F.: Terrier. F. J. Am. Chem. Soc, 1987. 109. 71157121 .

26. Spencer. T. A.: Kendal. M. C. R.: Reingold. I. D. J. Am. Chent Soc. 1972, 94, 12501-1254.

27. Bernasconi, C. F.: Murray, C. J. J. Am. Chem. Soc. 1986, 108. $5251-5257$

28. Bernasconi. C. F.: Leyes. A. E.: Eventova. I.: Rappoport. Z. J. Am Chem. Soc. 1995. 117. 1703-1711. 